\title{
Labor supply dynamics, unemployment and experience in the labor market
}

\author{
Étienne Wasmer* \\ UQAM, Montréal**
}

Economists concerned by the rise in European unemployment have paid little attention to the increase in the active population. One reason for this lack of interest is that relations between labor supply and unemployment cannot persist in the long run in representative agent models, since capital stock will increase endogenously, as will the productivity of labor. This is the conventional Solowian view applied to non-clearing labor markets. In some models, however, the size of the labor force can affect equilibrium unemployment through a composition effect. ${ }^{1}$

Precisely, one of the most substantive changes in the OECD labor markets since the 1960's is the massive entrance of women and the larger cohorts of young workers, which arguably, cannot be considered as homogeneous variations in the size of population. Section 1 will first document this trend, using French microeconomic data from Enquête Actifs Financiers 1992 , where information on true employment experience is available. Young and female workers have a smaller number of (efficient) units of employment experience. It is worth noting that important empirical works (Welch (1979), Bloom, Freeman and Korenman (1987), Murphy, Plant and Welch (1988) among others, and more recently Shimer (1998)) have similarly concluded to the importance of the adverse impact of the baby-boom cohorts

\footnotetext{
* Based on IIES Seminar Paper Series 98-651, IZA dp 463 with a slight change in the title. It is also based on two chapters of my PhD dissertation at the London School of Economics. The empirical part on French data was done at INSEE-CREST, the hospitality of which is gratefully acknowledged. I thank Christophe Soil for the simulation part.

** Other afiliations : CIRPEE and ECARES, UniversitĖ Libre de Bruxelles. Address : UniversitĖ du QuĖbec ¥ MontrĖal, DĖpartement des sciences Ėconomiques, Case postale 8888, Succursale Centre-Ville, MontrĖal (QuĖbec), CANADA H3C 3P8

1 This is the case in Pissarides (1990), where labor force growth affects equilibrium unemployment by increasing the share of young workers through more new entrants into the labor force. See also Nickell (1991), and, on relative wages, the theoretical part in Welch (1979).
} 
in the labor markets. ${ }^{2}$ It is regrettable to notice that there are few theoretical works on this question, since labor supply (composition and dynamics) and other labor market variables (such as unemployment, relative wages or human capital investment) interact in a complex way.

So, in the second part of the paper, I will attempt to clarify some of these interactions between labor supply, the level of employment and unemployment and the accumulation of labor market experience. Section 2 introduces the notations of a model of labor markets with endogenous participation, unemployment and human capital. Skills are provided through employment experience accumulation. Unskilled workers are young workers or older workers with insufficient experience. Unemployment arises from wage rigidities at the bottom of the distribution of wages. Section 3 introduces the dynamic of labor supply, defines the solution and the equilibria both in the short-run and in the long-run, and finally investigates the impact of two labor supply variables: the growth rate of population, taken exogenous, and the distribution of opportunity costs of participating to the labor market in the second period of workers' life. The latter is meant at capturing the trend in the propensity to participate to the labor market of marginally attached workers discussed in Section 2 .

The key result is that a labor market with large enough wage rigidities is unstable and leads to multiple equilibria. This result is obtained under constant returns to scale in production. Moreover, one reaches and stays in the low employment equilibrium after a large supply shock, even if this shock is a temporary one. This result is due to the intertemporal transmission of shocks through the skill composition of the labor force. Lower employment today leads to a lower number of skilled workers the following period since they are fewer to accumulate experience. This therefore reduces the demand for inexperienced workers and reduces youth employment. Endogenous participation plays a stabilizing role; when employment is too low, the unskilled older workers leave the labor force, freeing the labor market for younger workers. However, the multiplicity of equilibria remains. In a competitive labor market instead, wage flexibility breaks the vicious circle and allows young workers to start with lower wages but accumulate experience. This arises at the cost of higher wage inequality between experienced and inexperienced workers.

Note that this is not the first paper where this kind of intertemporal transmission of the shocks of the labour market is implicitly present; Pissarides (1992) and Ortega (2000) are two examples in a job matching framework. However, unlike the two previous papers, this model does not need search frictions, and its emphasis is on labor supply trends as initiators of the amplification of the shocks. It also goes further into the analysis of the composition of the supply of skills and notably of the role of labor market experience. To our knowledge, these are the only papers focusing on labor

2 Shimerê conclusion, notably, is that U.S. unemployment rate variations in time reiect partly the age composition of the labor force. 
market equilibria with a dynamic transmission of shocks from one period to another. There are several other papers in the literature where multiple equilibria arise due to market imperfections, but those papers differ from this one since there is no such intertemporal transmission of shocks. ${ }^{3}$

Finally, Section 4 concludes by discussing the limits of the theoretical results established here, notably the absence of an alternative channel for skill accumulation such as education ${ }^{4}$.

\section{Labor Supply}

In all OECD countries, there has been an increasing number of women in the labor force and, also to some extent, of the 25-34 year old workers. Various other measures of the age composition of the labor force indicate similar trends, with sometimes a tendency towards a re-increase in the average age of the labor force in the second half of the 80 ' $\mathrm{s}^{5}$.

To re-express these trends in terms of human capital implications, one can measure the change in the supply of experience based on macroeconomic labor market participation data, in adapting the perpetual inventory method. The outcome of this methodology (Wasmer 2001) indicates that most OECD countries indeed faced a decline of experience in the 70's, early 80 's, and then an increase in experience in the 90's.

Using alternative data based on French individual data, it is also possible to decompose the fitted hourly wage (from two wage equations for each gender) of all individuals in the labor force into two components, experience (on the $\mathrm{x}$-axis) and education (on the $\mathrm{y}$-axis) ${ }^{6}$. A quite large decline in the 'experience' component in wages during the period 1970-77 can be observed. In a second period, after 1977, the decrease in the average efficiency units of experience of the labor force decelerates, and there is a strong rise in the supply of education. I obtained very similar results for the US.

3 In another model of search frictions, duration dependance can also imply multiple equilibria (Coles and Masters, 2000). As they put it, êmltiplicity is possible through a skill composition effectsê. Either ir ms match fast with low skill workers or match slowly with good quality workers, the latter having not lost skilis. In the human capital literature, externalities also lead to multiple equilibria. Note here that we obtain multiple equilibria without relying on human capital externalities.

4 On education, and beyond the previous version of the present work (1997 for the PhD version and 2002 for a recent discussion paper), one can very usefully refer to several recent works. More speciically on the links between education and labor market impertections, one can read Charlot (2002) and Decreuse and Charlot (2003). On the interplay between education and experience in an OLG structure, one can refer to de la Croix and Docquier (2003). On OLG models with demographic trends and education, see Boucekkine et al. (2000). On the relation between endogenous participation and education choices, one can read Charlot (2003).

5 A more detailed description of these trends and the choice of the deinition of êyungeworkers can be found in the discussion paper version of this text.

6 Wasmer (1997) 
Here, I investigate the same issue with another microeconomic dataset for France, the survey 'Actifs Financiers 1992'. This is a unique dataset in which individuals declare their number of years in part-time and full time employment since the beginning of their working life. A description of the variables and the instruments is reported in appendix A. The goal here is to show the difference between real and potential experience (potential experience being age minus (imputed) age at the end of education, the usual proxy in $90 \%$ of the studies), and accordingly, to understand to what extent women can be considered as "young", i.e. low-experienced.

Table 1 reports real experience, potential experience and their relative difference (\% Gap) in different cells of the active population. The first row represents the average (potential or real) experience of all active men (or women), rows 2-5 sort individuals according to potential experience and the last four rows according to the quartile of hourly wage (in this case, the sample is restricted to the active employed workers). The third and sixth column give the relative difference between potential and real experience. Note that this gap reflects either the time spent out of activity, i.e. for older, less qualified women, or into unemployment.

It appears quite clearly from the table that in 1992, the average real experience of women was by $16 \%$ lower than their potential experience. When compared to men, it appears that the high-skill women actually have obtained experience levels similar to those of men : the relative gap between the real and the potential experience of women in the fourth quantile is $11 \%$, close to the men's average $(9.6 \%)$. Finally, young workers of both gender have faced difficulties to access their first job; the gap is $10.6 \%$ for men, and $17 \%$ for women. These averages in the different cells do not only reflect the participation behavior of workers in 1992 , but the entire participation history of these workers. The differences between actual and potential experience are much larger for the oldest women $(\exp >30)$, about $22 \%$, while the corresponding figure is $3.5 \%$ for men.

Beyond gross differences in experience across groups, the knowledge of the returns to real experience by gender is also informative. This notably provides an estimate of the number of efficiency units of experience supplied by different groups, by multiplying the return and the quantity of experience supplied by workers. Using a classical Mincer wage equation (Mincer 1974), one finds in Table 2 the following coefficients for experience (controlling for education with seven dummy variables) ${ }^{7}$.

Even when considering true experience instead of potential experience $^{8}$, it appears that after 20 years of employment experience (the median number of years of experience), the average return to experience is $3.34 \%$ a

7 The variables in the participation equation (Heckman) are (Age - Age of First Paid Activity) and its square, a dummy variable for being married, the number of children less than three, six and eighteen year old and a dummy for the participation of individuale mother. Using these variables to instrument real experience gives extremly similar results (available on request).

$B$ It is sometimes considered that potential experience is a good instrument for real experience. There is obviously a tradeoff between taking care of the correlation between real experience and the residuals, and 
Table 1 : France 1992, cell averages, men in the labor force

\begin{tabular}{lcccccc}
\hline & \multicolumn{3}{c}{ Men } & \multicolumn{4}{c}{ Women } \\
& Real Exp. & Pot. Exp. & \%Gap & Real Exp. & Pot. Exp. & \%Gap \\
\hline All & 20.7 & 22.9 & 0.096 & 17.8 & 21.4 & 0.168 \\
$\exp \leqslant 10$ & 5.9 & 6.6 & 0.106 & 5.3 & 6.4 & 0.172 \\
$11 \leqslant \exp \leqslant 20$ & 14.0 & 15.5 & 0.097 & 13.4 & 15.6 & 0.141 \\
$21 \leqslant \exp \leqslant 30$ & 23.3 & 25.2 & 0.075 & 21.9 & 25.3 & 0.134 \\
$\exp \geqslant 31$ & 33.2 & 34.4 & 0.035 & 29.7 & 37.9 & 0.216 \\
\hline
\end{tabular}

Table 2: France 1992, variable : Log Hourly Wage. Heteroskedasticity consistent standard error in parentheses.

\begin{tabular}{lccc}
\hline & Men GLS & Wom. GLS & Wom. Heckman \\
\hline Experience & $0.049(0.002)$ & $0.030(0.004)$ & $0.029(0.005)$ \\
Exp. Sq. $(\times 100)$ & $-0.078(0.005)$ & $-0.042(0.010)$ & $-0.038(0.011)$ \\
Inv. of Mill's ratio & - & - & $0.223(0.066)$ \\
$\mathrm{R}^{2}$ & 0.356 & 0.239 & 0.251 \\
$\mathrm{~N}$ obs & 3641 & 3108 & 2984 \\
\hline
\end{tabular}

year for men whereas it is $2.16 \%$ for women; the gender gap in the return to experience is about $45 \%$. Interestingly, this $45 \%$ figure is close to Mincer's estimates; he reports $(1997, \mathrm{p}$. S31) that he assumes the female investment ratio in human capital to be half of the corresponding figure for men. Depending on the sample (notably excluding the very low wage workers), the difference can sometimes be smaller than $45 \%$, but always remain above $30 \%$.

The natural conclusion is that, at the same level of employment experience, the 'efficient units' of experience supplied by women are $45 \%$ lower and accordingly an increasing relative supply of female workers, added to the increasing size of the cohorts of new entrants into the labor market, decrease the per-worker level of experience.

\section{$2 \quad$ A model}

Given the evidence presented in the previous section, representative agents' models cannot address the impact of labor supply trends on labor market outcomes. This section is devoted to building the simplest dynamic model

treating the systematic bias due to measurement error in experience (especially for women). These specilc issues are investigated in Wasmer (1997). 
which can incorporate the impact of heterogeneity in the supply trends on equilibrium unemployment. Note that the model presented here differs from the previous literature on the link between human capital theory and life-cycle decisions (e.g. Weiss 1986, Mincer 1997 and the subsequent references) in two ways: unemployment is introduced, and the aggregate returns to different skills are endogenous, since the focus of the paper is a macroeconomic one.

\subsection{Production technology}

There are only two broad types of occupations in the economy. The first occupation can be filled by everyone and the second cannot be filled by the unskilled and is thus restricted to the skilled workers. The production technology combines the skilled and the unskilled labor inputs. The efficiency units of employment of skilled workers are denoted by $E_{i}^{S}$, and the efficiency units of employment of unskilled workers by $E_{t}^{U}$. The constant return to scale production function of the representative firm will be : $F=$ $F\left(E_{t}^{S}, E_{t}^{U}, \tau\right)$, where $\tau$ is a technology parameter which represents biased technological progress raising the relative demand for skilled workers. Capital is ruled out; at a fixed interest rate, the above production function is the long-run reduced form of a more general technology with three factors, that is, capital, skilled and unskilled labor. Accordingly, marginal products can be expressed as functions $g^{i}$ and $g^{S}$ of the ratio of skilled to unskilled labor denoted by $z_{t}=E_{t}^{S} / E_{t}^{i}$ :

$$
\begin{aligned}
& g^{U}\left(z_{\imath}\right)=F_{U}\left(E_{t}^{S}, E_{t}^{U}, \tau\right) \\
& g^{S}\left(z_{t}\right)=F_{S}\left(E_{t}^{S}, E_{l}^{U}, \tau\right)
\end{aligned}
$$

with

$$
\begin{aligned}
& d g^{L}\left(z_{t}\right) / d z_{t}>0 \\
& d g^{S}\left(z_{t}\right) / d z_{t}<0
\end{aligned}
$$

\subsection{Workers}

Cohorts of size $P_{l}$ of agents enter the labor market at time $t$. The growth rate of the cohorts is $n_{t}{ }^{10}$. The agents live two periods. In the spirit of Welch (1979), workers move from the low to the high occupation between the first and second period of life. provided that they can accumulate enough human capital. There are a priori two ways of accumulating human capital. The

9 This is a commonly invoked explanation for the rise in inequality in the US, e.g. Juhn, Murphy and Pierce (1993) and Katz and Murphy (1992).

10 Given that agents live two periods and that yearly population growth is around $1 \%$, one can think of $n_{t}$ as being the growth rate of population over 25 years, i.e. around 0.28 . 
first is to spend the first period of one's life in education and work the second period. The second is to obtain employment experience in first period. Further, experience accumulation can be made endogenous by introducing on-the job training decisions.

To expose the paper in the simplest possible way, some of the channels described above are ignored and notably all individual human capital margins are shut down. This concerns education : all workers start with the same level of schooling. This also concerns on-the job training. Note however that this does not imply that experience accumulation is exogenous. It is endogenous and will notably depend on the aggregate state of the labor market. This is sufficient to highlight the main mechanism of the paper at a low analytical cost. The reader interested in those individual human capital decisions and in the interaction between experience and education can refer to the earlier versions of this work in which these issues were fully addressed or in the literature listed in footnote 4 . They are briefly summarized in the concluding comments of Section 4 .

As a result of modelling choices, workers in the second period of their life can be in three different situations. They can be 1 . experienced; 2 . inexperienced and uneducated; finally, they can be 3 . out of the labor force. The skilled workers belong to category 1 , the unskilled to category 2 . I will denote the experienced workers by $E x$, the old unskilled (inexperienced and uneducated) by $O$, and the young workers by $Y$.

To keep the model simple, the young workers $\left(E_{t}^{Y}\right)$ and the old unskilled workers $\left(E_{t}^{O}\right)$ are perfect substitutes in the production, $E_{t}^{U}=$ $E_{t}^{Y}+E_{t}^{O}$. This means that, whatever the reason for not having accumulated experience (unemployment, inactivity or simply being in one's first period), workers are neither discriminated nor have suffered any human capital loss. This is an important difference to previous works assuming that unemployment duration has a specific adverse impact on workers, as in Pissarides (1992).

Since the focus of this paper is a macroeconomic one, I present here only a quite 'crude' description of experience accumulation, compared to the literature summarized by Weiss (1986). I assume that only a fraction $e_{\ell}=$ $1-u_{t}$ of a cohort of young workers can get enough employment experience to be considered as skilled next period, where $u_{t}$ is the unemployment rate for young workers. ${ }^{11}$ The convenient notation $e_{i}=1-u_{t}$ represents the employment to labor force ratio of the unskilled workers. Note also that

11 Linearity in $e_{l}$ is chosen so that the exposition of the argument is simplited, but a more general speciication would lead to the same results. Assume, for instance, that each period is subdivided into $p$ smaller subperiods where a lottery is held each time to randomly distribute jobs across workers. The experience level to access the skilled jobs could be $q$ successive spells of employment, with $q<p$. Then, the fraction of workers who access skilled jobs is a function $\Phi\left(u_{l}, p, q\right)$, with $\Phi_{1}>0, \Phi_{2}>0$ and $\Phi_{3}<0$. What simply matters to obtain the main result of the paper is that the aggregate outcome at a (big) period $t$ depends strongly on past outcomes. This only requires agents who live two periods. More realism could be introduced by modelling more than two periods, at the cost of additional complexity and without qualitative changes. An alternative route, explored in Wasmer (2002) section 4.2, is to model on-the-job investments and their determinants. Multiple equilibria still come out from this more general speciication. 
given the perfect substitutability in production and the assumption of an absence of discrimination towards older unskilled workers, the quantities $u_{t}$ and $\epsilon_{t}$ refer to both young workers and old unskilled workers, even though later on, by an abuse of language, $e_{l}$, will be called the employment rate.

\subsection{Unemployment}

The wage of the unskilled may not always be market-clearing, due to some downwards rigidities. Unemployment only affects the unskilled; the wages of the skilled are market-clearing. The wage rigidity can be linked to the existence of a wage setting curve, linking wages and unemployment as in efficiency wages model, to the existence of Nash-Bargaining linked to search frictions, the existence of unions setting wages given the labor demand curve of the firms, or risk-averse workers buying an insurance to risk-neutral firms. A frequent short-cut to get a non-market-clearing wage for the unskilled is to assume that it decreases with unemployment, like in the wage curve models. Here, we follow an early literature (Layard et al. 1991) and think of wages in the unskilled labor market as being represented by a double log functional form, of the type

$$
\ln \left(w_{t}^{i}\right)=b-\phi \cdot \ln \left(1-e_{t}\right)
$$

The results of the model remain the same if one instead chooses a log linear formulation for the wage curve. Given that skilled workers can apply to unskilled jobs, we have to check ex-post that $w_{t}^{i}<w_{t}^{S}$. In the proof of Proposition 2, we offer a simple condition on the parameter reflecting the relative demand for skilled workers.

Among the alternative ways of introducing wage rigidity, one can cite Saint-Paul (1995): he assumes the existence of a minimum wage indexed on the average wage (as the French minimum wage, for instance). This mechanism has been investigated : in this model with two types of workers, this is equivalent to having a maximum dispersion of wages, i.e. a constant indexation rate $\gamma<1$ and the condition on wages writes $w^{U} \geqslant \gamma \cdot w^{S}$. This yields to simpler results yet less rich features, as one of the long-run equilibria defined later on explicitly depends on the limit of unskilled wages when $e_{t}$ approaches one ${ }^{12}$. We will thus use equation (3) except when we introduce the competitive labor market as a benchmark (next Section), in which case wages will be fully downward flexible regardless of the level of unskilled employment.

12 An alternative specilcation would be to model a formal game of wage bargaining, at some additional complexity cost and without many more insights on the dynamics of skill accumulation. 


\subsection{Endogenous participation}

Participation is modelled as a static extension of the neoclassical model of labor supply. The value of non-market time of workers is assumed to be age-dependent. In the first period of time, this value is denoted by $\Lambda_{1}$ which has the interpretation of a reservation wage. In the second period, it is denoted by $\Lambda_{2}$. We assume that $\Lambda_{2}>\Lambda_{1}$, as older workers find effort more costly. Furthermore, $\Lambda_{1}$ is assumed to be close enough to zero so that conveniently, in the first period of life, young workers will all participate to the labor market. This is an empirical fact: the participation rates of workers not enrolled in education are higher at lower ages and then decline with time ${ }^{13}$.

This reservation wage is a pecuniary equivalent of utility when the worker is not in the labor force. In the second period, workers will participate if the expected wage is higher than the reservation wage. The participation rate of the unskilled in the second period is thus simply, either one or less than one. In the latter case, $\epsilon_{\ell}$ decreases so that the expected wage is equal to the reservation wage. Formally,

$$
\begin{gathered}
\rho_{t}^{O}=1 \text { if } e_{t} w_{t}^{O}>\Lambda_{2} \text { or, } \\
e_{t} w_{t}^{O}=\Lambda_{2} \text { and } 0<\rho_{t}^{O}<1 .
\end{gathered}
$$

Similarly, the participation rate of skilled workers is $\rho^{E x p}=1$ if $w_{t}^{S}>\Lambda_{2}$ and between 0 and 1 if $w_{t}^{S}=\Lambda_{2}$. Given that we only consider situations for which $w_{t}^{U}<w_{t}^{S}, w_{t}^{S}=\Lambda_{2}$ would imply $w_{t}^{U}<\Lambda_{2}$ i.e. that old unskilled workers all retire from the labor force $\left(\rho^{O}=0\right)$, a degenerated situation we prefer not to consider here. This implies that from now on, $\rho^{E x p}=1$.

We have thus here two variables describing the composition of labor supply and the trend to more inexperienced workers : $n_{t}$ and $\Lambda_{2}$. An increase in $n_{t}$ is associated with a younger labor force. The second channel is more subtle. In a male-dominated labor force, one expects $\Lambda_{2}$ to be very low. As women with recurrent interruptions of labor market activity enter the labor market, the average $\Lambda_{2}$ in the economy should raise.

\section{The setup}

\subsection{Dynamics of labor supply and employment}

The labor supply of skilled workers is simply the number of the old experienced workers, $L_{t}^{S}=L_{t}^{E x}$. The unskilled workers are both the young

13 In Wasmer (1998), I introduced at the beginning of the second period a shock on leisure (birth, disease), leading to a distribution of reservation wages $w^{r}$ in the population, with a cumulative density function. In order to simplify the exposition, I take here the degenerate distribution. The proofs are much simpliied and the main results are preserved. 
workers and the old inexperienced ones. Unskilled labor supply is therefore the sum the two categories: $L_{t}^{U}=L_{t}^{Y}+L_{l}^{O}$.

Given the existence of unemployment among the unskilled, the time structure of the model provides the following dynamic labor supply equations :

$$
\begin{aligned}
L_{t}^{E x} & =P_{t-1} \cdot e_{t-1} \\
L_{t}^{O} & =P_{t-1} \cdot\left(1-e_{t-1}\right) \cdot \rho_{t}^{O} \\
L_{t}^{Y} & =P_{t},
\end{aligned}
$$

Eq. (4) indicates that the experienced workers who participate are the young employed participants of the previous period, i.e. $L_{t-1}^{Y}$ multiplied by their probability of having been employed $e_{t-1}$. A similar interpretation holds for (5), reminding that $\rho_{t}^{O}$ is the participation rate of old, unskilled workers. Eq. (6) states that the entire cohort of young workers participate and thus labor supply equals the size of the cohort.

In terms of employment, full employment of skilled workers and the definition of the employment rate of the unskilled workers imply that

$$
\begin{aligned}
& E_{t}^{S}=L_{t}^{E x} \\
& E_{l}^{U}=e_{t} L_{t}^{U}
\end{aligned}
$$

or in terms of ratio of skilled to unskilled employment $z_{t}$ :

$$
z_{l}=\frac{P_{t-1} e_{t-1}}{e_{t}\left[P_{t}+P_{t-1} \cdot\left(1-e_{t-1}\right) \cdot \rho_{t}^{O}\right]}=\frac{e_{t-1} / e_{t}}{1+n_{t}+\left(1-e_{t-1}\right) \rho_{t}^{O}}
$$

\subsection{Solution}

The equilibrium at time $t$ involves the knowledge of $\left(z_{t}, e_{t}, \rho_{t}^{O}, w_{t}^{U}, w_{t}^{S}\right)$. Once $z_{t}$ is determined as a function of $e_{t}$ and $\rho_{t}^{O}$ for a given $e_{t-1}$, equations (1) provide the marginal product of all groups of workers. Conditional on the wage determination rule, either competitive determination or a wage curve (3), this provides the level of employment $e_{t}$ of the unskilled through the standard equalization of the marginal product

$$
w_{i}^{U}=g^{U}\left(z_{t}\right)
$$

while the participation rate of the older unskilled workers is determined though equation (4). In other words, $e_{t}$ and $\rho_{t}^{O}$ are functions of $z_{t}$ for all $t$. Equation (7) thus implies a dynamic link between $z_{t}$ and $z_{t-1}$ or equivalently between $e_{l}$ and $e_{t-1}$ which can be thought as a short-run equilibrium. Given decreasing returns to scale, relative labor demand curves are downward sloping with respect to employment. If the wage is competitively determined, 
labor supply of the unskilled is upward sloping with a kink in $\Lambda_{2}$. If the wage follows equation (3), instead it is upward sloping in unskilled employment. So, the link between $e_{t}$ and $e_{t-1}$ is unique in each of the two possible participation regimes defined formally now.

Definition Regime FP is defined as the Full Participation regime, i.e. the participation rate of the old unskilled workers $\rho_{t}^{O}$ equals 1 . Regime 2 has instead $\rho_{t}^{O}<1$ and is called the Partial Participation regime (PP).

We can also define a long-run equilibrium as a situation in which, if $n_{t}$ is constant to a steady-value, $e_{t}=e_{t-1}$ or $z_{t}=z_{t-1}$ and thus wages and participation levels are constant. As we now show, multiple long-run equilibria may arise.

\subsection{Competitive wages}

While wage rigidity are a more accurate representation of a European labor market, it is better to start with a market-clearing labor market, as a benchmark. In this case, wages of the unskilled are able to decline enough for full employment to hold in all cases, implying $e_{t} \equiv 1$. Accordingly, $z_{\ell}=1 /\left(1+n_{t}\right)$ and all older workers have accumulated experience in the first period of life. Accordingly, they are all skilled workers. Since we assumed that $\rho^{E x p}=1$, only the full-participation regime holds here.

Proposition 1 When wages are competitive, there is a unique long-run equilibrium. A higher $n$ increases inequality.

Proof Wages are equal to the marginal productivity of labor at full-employment - this for every $t$. The wage of the unskilled is determined by $w_{t}^{U}=g^{U}\left(z_{t}\right)=$ $g^{U}\left(\frac{1}{1+n_{t}}\right)$. The wage of the skilled workers is given by $w_{t}^{S}=g^{S}\left(z_{t}\right)=g^{S}\left(\frac{1}{1+n_{t}}\right)$. In the long-run, i.e. when $n_{t}=n$, a higher $n$ thus raises the relative wage of skilled to the unskilled $w^{S} / w^{U}$, given inequalities (2).

The intuition is that a increase in $n$ is an increase in the supply of young workers. This reduces their absolute and relative wage since the wage of the skilled (experienced) workers is increased. Since there is full employment, the employment to labor force ratio is identically equal to one. A fact supporting Proposition 1 is the increase in the wage return to experience in the US over time, as reported in Juhn et al. (1993) ${ }^{\mathbf{1 4}}$, for instance. Since 1963, the return to experience has increased a lot, to a much larger extent than the return to education. As indicated in Section 1, there has also been a decline in the supply of 'experience'. It is tempting to see a causality at this stage : a lower supply of skills (experience) increases the return to experience.

14 See also Acemoglu (2002) and Gottschalk (1997) for more recent evidence on wage inequality. 
What about dynamic issues? In the short-run, the skill composition of the labor force $z_{l}$ depends on $n_{t}$, but not on $z_{t-1}$ and thus does not exhibit a particularly rich dynamic pattern. Accordingly, this flexible economy, with full employment and uniqueness of a long-run equilibrium, faces no persistence of temporary supply shocks.

\subsection{A non-market-clearing labor market}

Things are very different in a world in which wages exhibit some wage rigidity. Equation (3) implies that $w_{t}^{U}$ goes to infinity when $e_{t}$ goes to 1 , implying that there will always exist some positive level of unemployment at any time $t$. The dynamics of this economy can be summarized by the dynamics of this variable $e_{t}$, by Proposition 2 :

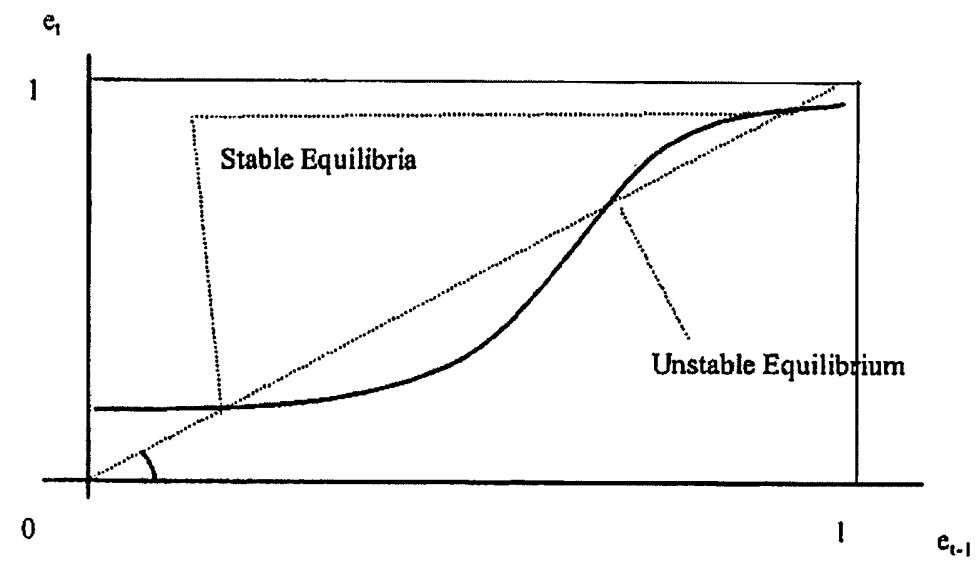

Figure 1: Dynamic of the economy: the employment rate $e_{t}$ of the unskilled as a function of past period employment $e_{t-1}$ and 45 degree line.

Proposition 2 The dynamic of the economy is described by a function $e_{t}\left(e_{t-1}\right)$. This function has a flat part corresponding to regime PP i.e. when the participation rate of unskilled workers is below 1. The limit of $e_{\ell}$ when $e_{t-1}$ goes to 1 is strictly below 1. In between, the slope of $e_{t}\left(e_{t-1}\right)$ is always strictly positive, can be very large and thus may intersect the $45^{\circ}$ line more than once. In the generic case, we have multiple long-run equilibria. See the dynamics of employment in Figure 1. If the curve intersects the $45^{\circ}$ line once only, there would only be one long-run equilibrium.

Proof The proof is in four steps and two lemmas.

a) Link between $e_{t}$ and $e_{t-1}$. We have as a first order condition that

$$
w_{t}^{U}=g^{i}\left(z_{t}\right)
$$


where $z_{t}$ is the current ratio of skilled to unskilled workers. Using the double log-wage equation (3), we thus obtain

$$
\exp (b)\left(1-e_{t}\right)^{-Q}=g^{V}\left(\frac{e_{t-1} / e_{t}}{1+n_{t}+\left(1-e_{t-1}\right) \rho_{t}^{O}}\right)
$$

b) Hierarchy in wages : $w_{t}^{i}<w_{t}^{S}$ when $e_{t}$ tends to 1 . See Appendix B.

c) Existence of a regime PP, i.e. $\rho_{t}^{O}<1$.

d) Properties of the full-participation regime FP, i.e. $\rho_{t}^{O}=1$. In the fullparticipation regime, we have

$$
b-\phi \ln \left(1-e_{t}\right)=\ln g^{U}\left\{e_{t-1} /\left[e_{t}\left(2+n_{t}-e_{t-1}\right)\right]\right\}
$$

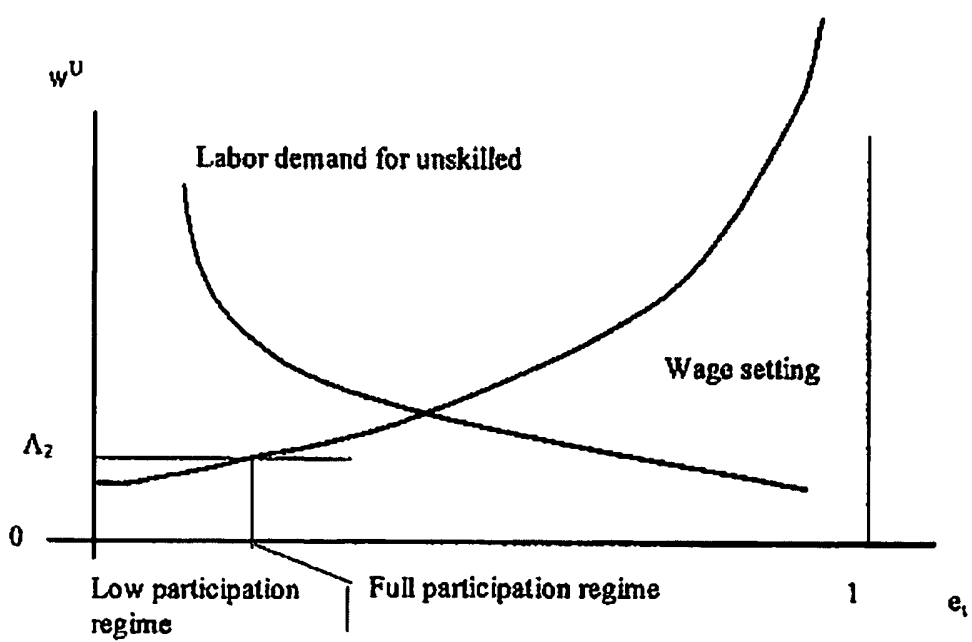

Figure 2: Short-run equilibrum for $e_{t}:$ Labor demand for the unskilled as a function of the stock of experience (depending of $e_{t-1}$ ) and the wage curve.

The left-and side is a wage setting curve, increasing in $e_{t}$. The righthand side is the labor demand function, representing the demand for unskilled workers. It is decreasing in $e_{t}$ by concavity of $F$ (i.e. $F_{U U}<0$ ). This labor demand curve is also shifted up by higher $e_{t-1}$ and by lower $n_{t}$, and finally, by lower $\tau$ (the parameter reflecting the relative demand for skilled workers). A higher $e_{t-1}$ simply means more skilled workers at time $t$, and thus, given complementarity between skilled and unskilled, higher relative demand for unskilled workers. A higher $n_{t}$ simply means more competition among the unskilled, and thus lower employment. See Figure 2 for an illustration. Coming back to equation (10), one sees (formally in Lemma 2 in Appendix B) that it implies a dynamic link between $e_{t}$ and $e_{t-1}$ which is increasing as soon as $F_{u s}>0$ which was assumed in Section 2.1. Further, the limit $e_{t}=1$ is never reached : $e_{t}\left(e_{t-1}=1\right)<1$. The interpretation is simply that wage pressures are so large at full employment that this can never be a stable equilibrium. 
e) Local convexity of $e_{t}\left(e_{t-1}\right)$. To verify the convexity, we need to compute the second order derivative $\frac{d^{2} e_{1}}{d e_{t-1}^{2}}$ which implies third order derivatives in the production function. We thus have no interesting results in the general case and the function can take all concavities. We can look at a more specific (CobbDouglas) case. Then we have the following dynamic link between $e_{t}$ and $e_{t-1}$.

$$
\alpha \ln e_{t}-\phi \ln \left(1-e_{t}\right)+b=\ln (1-\alpha)+\alpha\left[\ln e_{t-1}-\ln \left(2+n_{t}-e_{t-1}\right)\right]
$$

One is referred to appendix $B$ for the second order derivatives calculations. One can simply note that a simulation of (11) with $\Lambda_{2}=0, \alpha=0.5, \phi=0.1$ and $b=-0.96$ leads to three intersections with the $45^{\circ}$ line, and so to three equilibria $\left(e=0, e=0.57\right.$ and $e=0.86$ ). With a positive value for $\Lambda_{2}$, the three intersection occur at $e=0.5, e=0.57$ and $e=0.86$.

a

The model offers the possibility of multiple equilibria, and more specifically, the possibility of both a low-employment equilibrium and a highemployment equilibrium. As indicated in point e) above and in Appendix $B$, conditions on parameters for the existence of multiple equilibria involve third-order derivatives of $F$ and are not provided, as they are not particularly interesting. The possibility of multiple equilibria (e.g. the claim of the proposition) is demonstrated thanks to the numerical resolution in e).

The intuition for the multiplicity of equilibria is simple : there is an intertemporal amplification of shocks, through the skill composition of the labor force. If there is low employment in a given point in time, the next period level of skilled workers will be low since fewer workers accumulate experience. So, the demand for unskilled remains weak, employment is low and participation to the labor market is low too. The high employment equilibrium has just the opposite properties : high level of skilled workers, so high demand for unskilled, and so on...

\subsection{Stability}

When there are multiple equilibria, the stability of the equilibrium is determined by the slope of $e_{t}\left(e_{t-1}\right)$ at the intersection with the 45 degree line.

Corollary 1 The lowest employment and the highest employment equilibria, when they exist, are both stable.

Proof The slope of $e_{t}\left(e_{t-1}\right)$ is always positive. The equilibrium is thus stable if and only if the slope is smaller than 1 . The low employment equilibrium (to the left of Figure 1) is stable due to the existence of a flat part in $e_{t}\left(e_{t-1}\right)$ itself due to the downwards adjustment of labor market participation when unskilled employment is too low. The stability of the high employment equilibrium is insured by the wage pressure of unskilled workers: suppose that the slope of $e_{t}\left(e_{t-1}\right)$ is larger than 1 around the highest employment equilibrium. A temporary increase in $e_{1}$ 
around that equilibrium value would be amplified, and $e_{t}$ would converge to 1 , which is impossible given Lemma 2 in the proof of Proposition 2.

口

One can derive another corollary to Proposition 2 :

Corollary $2 A$ temporary shock on $n_{t}$, if sufficiently large, can lead to a permanent change of equilibrium. Static adverse effects like a lower equilibrium employment or lower participation are driven by larger cohorts $n_{t}$, a higher demand for skills raising $g^{S}$ relative to $g^{U}$ at a given $z_{t}$ and, higher unskilled wage pressures b. Dynamic adverse effects (the existence of a low employment equilibrium and the convergence to it) are driven by the irreversibility of skill loss due to unemployment, and are reinforced by a higher $n_{t}$, higher demand for skills and higher $b$.

Proof All the effects above shift the relative demand for skilled workers and thus imply a temporary decrease in the curve $e_{t}\left(e_{t-1}\right)$. See Figure 3 for an illustration with higher $n_{t}$. Starting from $\mathrm{A}$, if the curves moves downwards, $e_{t}$ evolves temporarily below the 45 degree line. If $e_{t}$ becomes lower than a cutoff value (defined by the unstable, intermediate intersection between the original curve and the 45 degree line), then $e_{t}$ irreversibly converges to $\mathrm{B}$.

口

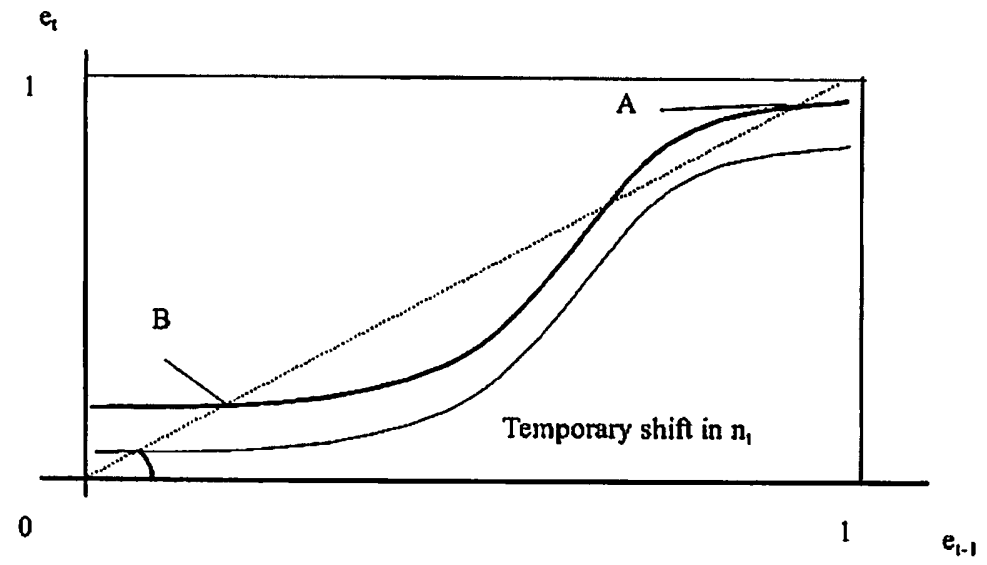

Figure 3 : Dynamics of transition from one long-run equilibrium to another with a temporary or a permament supply shock.

The permanent effect of a temporary shock deserves some further comments. In figure 3 , a temporary downward shift of the curve $e_{t}\left(e_{t-1}\right)$ may lear: to a permanent change of equilibrium, if the temporary level of employment $e_{t}$ is on the left side of the unstable equilibrium (the one in the middle of the graph). In this case, the level of employment converges to the low equilibrium. The economic intuition is the same as the intuition for the multiplicity of equilibria : the temporary supply shock 
increases unemployment among young/low-experience workers. On average, the young cohorts accumulate less experience, the supply of skills the next period is lower, which reduces the demand for unskilled workers. When the temporary shocks disappear, the labor force still exhibits some trace of the shock, which is simply that the labor force as on average a low level of experience. If the initial shock was too big, the economy cannot recover the previous high equilibrium employment and instead shifts to the low employment equilibrium.

This persistence and amplification of the shocks may characterize well the situation of Spanish or Italian southern regions in the 80's, or Irish peripheral regions before the spectacular growth performance of the 90 's. A combination of high demographic growth, rigid wage scales and very large unemployment rates (40\% to $50 \%$ are not unusual among young workers) self-reinforced their effects by dynamically reducing the quality of the labor force, due to the absence of learning on-the-job, or more generally, of works habits.

\section{Concluding comments}

It has been argued here that not all the consequences of the coincidence of rising female participation and the baby-boom have been explored. This work can be seen as a first step in this direction. The section above has illustrated the key difference between an economy with rigid wages and an economy with flexible wages: in the former, a big supply shock generates crowding out in the market for inexperienced workers, and thus prevents young workers from accumulating experience, reduces the employment opportunities of older workers and reduces their participation rates. The economy cannot recover from the big temporary supply shock and remains stuck to the low employment/low participation equilibrium. Southern European experiences may fit this description quite well. Although we have not explored this possibility here, massive withdrawal from the labor market by youngsters may lead to the same adverse consequences as in a rigid labor market. By contrast, the flexible economy accepts some wage inequality between experienced and inexperienced, but offer them experience which is thus dynamically more efficient.

Among these results, there are two which deserve further comments since they can be tested. First, in partial equilibrium, participation and unemployment rates are negatively linked, since participation decisions are endogenous and negatively depend on unemployment. The full equilibrium resuit is more difficult to derive here. This actually implies that the test of the link between unemployment and labor supply should deal with a classical simultaneous equation problem, a difficulty acknowledged in Wasmer (1997, ch. 2). Second, in the stable upper steady-state equilibrium, the growth rate of the cohorts is positively correlated with unemployment. 
Another extension would be to investigate what happens if two components of human capital investments (schooling and on-the-job training) are added up to the framework. Such questions were directly addressed in a previous version of the paper (Wasmer 2002). The main conclusion of that section was that on-the-job training decisions still bring multiple equilibria, while education choices can partly undo the result and restore unique equilibria when education is a complementary input to unskilled labour. Indeed. when the market for unskilled labour is sufficiently crowded and slack, private returns to education becomes very high, which raises the supply of skills in the economy and by complementarity, the demand for unskilled. On-the-job training cannot play the same role as education since, in a slack labour market, only a fraction of the population, those employed, can access to skills : a low employment - low training equilibrium thus still exists. These extensions generate additional predictions : first, higher education of the workforce is indirectly caused by labor supply trends. And second, higher investment in human capital from 'low-experience groups' like women in response to adverse supply shocks reduces gender differences, but the faster, the lower unemployment. As unemployment is high, convergence in experience is much slower.

What about the relevance of the study of labor supply trends? First, note that among countries with fairly similar wage-setting institutions (e.g. continental Europe), low unemployment countries are those with a weak demography in the 70's and the early 80's (Scandinavian countries, Germany) as opposed to France or Spain, and the growth of female participation should be positively associated with unemployment. Similarly, many authors have acknowledged than the peak in the sizes of the cohorts in the 70's has had consequences for the US wage distribution (see, for instance, Welch (1979), Murphy, Plant and Welch (1988)) and for the unemployment rates (Bloom, Freeman and Korenman (1987)). The theoretical model of the previous sections was precisely based on these contributions, and has been extended in two directions : female participation as an explicit component of the supply trend; and the exploration of the links between the supply of education and the supply of experience. 


\section{Appendix}

\section{A Survey 'Actifs Financiers 1992'}

In the survey Actifs Financiers 1992, individuals are asked about their past, notably the age at end of schooling, the age of the first paid job, the number of periods of employment interruptions, the reason for these interruptions (unemployment, inactivity or disease), and finally, real employment experience as measured by the number of years in employment (defined as paid activity excluding "Petits boulots") and the number of years in full-time employment. This is quite unique in micro-surveys, since employment experience is usually approximated by the potential experience or Mincer's proxy (age - education - 5 or 6). Education is defined by the highest diploma obtained in general or vocational classes, and if there is no diploma, the level reached. It is defined by eight dummy variables (No Diploma, CEP, CAP or BEP, BEPC, Bac Technique, Bac General, Deug-Licence, Maitrise and higher) which correspond to 5 years of schooling, 8 years vocational, 8 years general, 12 years vocational, 12 years general, 14 years and more than 15 years. This gives a balanced partition of the sample. Annual wage earnings for 1990 include premia and wages from temporary employment and secondary activities. Individuals declare the corresponding number of months, as well as the percentage with respect to full-time employment. There is no problem of topcoding here. One is referred to Wasmer 1998 for the name of all these variables in the survey. The sample is restricted to $15-65$ year old workers who are not retired. About $10 \%$ of the sample whose current or last activity is self-employment, are excluded, since the return to experience in this type of activity may differ from the return to paid activity.

\section{B Proofs}

\section{B.1 Proposition 2, point b)}

Since the wage of the unskilled goes to infinity when $e_{\ell}$ tends to 1 , we have to check that the wage of the skilled workers does not become lower than the wage of the unskilled (otherwise, some skilled workers would apply to unskilled jobs). This is easy, the intuition is that, as wages increase due to wage pressure, along these relative demand curves, the demand for both labor is reduced, so that the hierarchy on wages remain the same. Formally, we can prove that $w_{t}^{i} / w_{l}^{S}$ remains bounded and lower than 1 when $e_{t}$ tends to 1 . Indeed, if $e_{t}$ tends to 1 , unskilled wages are large and this implies first full participation to the labor market, i.e. $\rho_{l}^{P}=1$. The ratio of first order-conditions states that

$$
\frac{w_{t}^{\ell !}}{w_{t}^{S}}=\frac{g^{l i}\left(z_{t}\right)}{g^{S}\left(z_{t}\right)}=r\left(z_{t}\right)
$$

where $r$ is an increasing function of $z_{t}$ which becomes in FP regime $\frac{r+1 / c_{t}}{1+n_{t}+(1)-r_{t}-1}$. Thus, $z_{t}$ converges to $e_{t-1} /\left(2+n_{t}-e_{t-1}\right)$ and is thus smaller than $1 /\left(1+n_{t}\right)$, and so $w_{t}^{i} / w_{t}^{s}<r\left(1 /\left(1+n_{t}\right)\right)$. For any given $n_{t}>-1$, there is a production technology such that the relative demand for unskilled labor is sufficiently low. A sufficient condition is thus $r\left(1 /\left(1+n_{t}\right)\right)<1$, where $r$ is the ratio of marginal products, QED. 
To illustrate this point, consider for instance a Cobb-Douglas production function, $\ln F=\alpha \ln E_{t}^{S}+(1-\alpha) \ln E_{t}^{U^{\prime 15}}$, and we have

$$
\frac{w_{t}^{U}}{w_{t}^{S}}=\frac{1-\alpha}{\alpha} \frac{e_{t-1}}{e_{t}\left(2+n_{t}-e_{t-1}\right)}<\frac{1-\alpha}{\alpha} \frac{1}{\left(1+n_{t}\right) e_{t}} \text { for all } e_{t-1}<1
$$

When $e_{t}$ is sufficiently close to 1 , say larger than $1-\varepsilon$ for an arbitrarily small $\varepsilon>0$, then $\frac{w_{t}^{c}}{w_{t}^{s}}<1$ if $\alpha>\frac{1}{1+\frac{1}{\left(1+n_{t}\right)(1-c)}}$. As $\varepsilon$ goes to 1 , and if $n_{t}=(1+0.01)^{25}=0.28$, the wage of the skilled remains above the unskilled if $\alpha>0.56$.

\section{B.2 Proposition 2, point c)}

Lemma 1 There exists a range of values of $e_{1-1}$ between 0 and a value denoted by $e_{t-1}^{\text {sup }}$ for which $e_{t}$ is a constant of both time and of $e_{t-1}$. Let us denoted it by $\bar{e}$. If parameters are such that $\bar{e}<e_{t-1}^{\mathrm{sil}}$ then, at constant growth rate $n$, there exists a stable equilibrium given by the intersection of the straight line $e_{t}=\bar{e}$ and of the 45 degree line. One can also determine the participation rates such that, at constant growth rate $n, e_{t}=e_{t-1}=f\left(\right.$ technology, $\left.n, \phi, \Lambda_{2}\right)$.

Proof Indeed, in the partial participation regime, we have from equation (3) that $e_{t} w_{t}^{\ell}=\Lambda_{2}$. Using (3), this implies $\Lambda_{2}=e_{t} e^{b-\phi \ln \left(1-e_{t}\right)}$ and thus $e_{t}$ is a constant denoted by $\bar{e}$, uniquely determined by $\ln \bar{e}+\ln b-\phi \ln (1-\bar{e})=\ln \Lambda_{2}$ as the left-hand side is increasing from $-\infty$ to $+\infty$. Using equation (9), we obtain $\Lambda_{2}=g^{V}\left(\frac{e_{t-1} / \vec{e}}{1+n_{t}+\left(1-e_{t-1}\right) p_{t}}\right)$. The right-hand side is increasing in $e_{t-1}$ and decreasing in $\rho_{\ell}$. Thus, the participation rate $\rho_{t}^{O}$ is increasing in $e_{t-1}$. The limit $e_{t \rightarrow 1}^{\text {sup }}$ at which all unskilled workers participate is determined by $\rho_{t}=1$, thus defined by $\Lambda_{2}=g^{v}\left(\frac{e_{t-1}^{\text {sup }} / \bar{e}}{2+n_{t}-e_{t-1}^{\mathrm{stI}}}\right)$. Thus, $e_{t-1}^{\text {sup }}$ can be larger or smaller than $\bar{e}$. If $\bar{e}<e_{t-1}^{\mathrm{sup}}$, then the flat part in $e_{t}\left(e_{t-1}\right)=e$ crosses the 45 degree line and thus there exists a stationary participation rate $\bar{\rho}<1$ for the old unskilled, such that there is a stable employment rate $e_{1-1}(\bar{\rho})=\bar{e}$. This participation rate is determined by $\Lambda_{2}=g^{U}\left(\frac{1}{1+n_{\ell}+(1-\bar{e}) \bar{p}}\right)$.

口

\section{B.3 Proposition 2, point d)}

Lemma 2 In the full-participation regime, we have a dynamic link between $e_{t}$ and $e_{t-1}$ which is positive. The limit $e_{t}=1$ is never reached: $e_{t}\left(e_{t-1}=1\right)<1$.

Proof Differentiating with respect to $e_{t}$ and $e_{t-1}$, we obtain $\frac{d e_{t}}{d e_{t-1}}=$

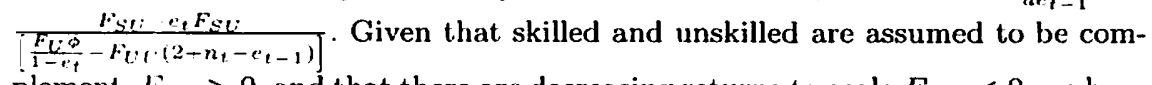
plement, $F_{S U}>0$, and that there are decreasing returns to scale $F_{U U}<0$, we have in all cases that $e_{t}$ is increasing in $e_{t-1}$. When -1 approaches one, the right-hand side of $(10)$ is equal to $\ln F_{2}\left(1, e_{t}\left(1+n_{t}\right)\right)$. To the extent that the production function has no infinite slope for finite values of the arguments, that value is bounded. Since the ieft-hand side of $(10)$ goes to infinity in 1 , this implies that there exists a finite, smaller than 1 limit for $e_{t}$ when $e_{t-1}$ goes to 1 .

15 In that case the technology parameter $\tau$ deined in Section 2.1 is simply $\alpha$. 
B.4 Proposition 2, point c) : concavity of $e_{t}\left(e_{t-1}\right)$ with a Cobb-Douglas production function

Differentiating equation (11), using the more convenient notation $y=e_{t}$ and $x=e_{\ell-1}$, one finds $\frac{d y}{d x}=\frac{\frac{1}{x}+\frac{1}{2+n_{\ell}-x}}{\frac{\phi_{0} / x}{1-y}+\frac{1}{y}}>0$ and

$$
\operatorname{sgn}\left(\frac{d^{2} y}{d x^{2}}\right)=\operatorname{sgn}\left[\frac{-1 / x^{2}+1 /(2+n-x)^{2}}{1 / x+1 /(2+n-x)}+\frac{-\phi / a(1-y(x))^{-2}+1 / y^{2}(x)}{\phi / \alpha(1-y(x))^{-1}+1 / y(x)}\right]
$$

When $x$ is close to zero, the negative terms dominate, but, given endogenous participation, we know that $x>e_{t-1}^{\mathrm{sup}}$ defined in Lemma 1 . Overall, and depending on the values of the parameters and notably of technology, we may have the different cases discussed in the Proposition, some of them represented in Figure 1. 


\section{References}

Acemoglu D. (2002), "Technical Change, Inequality, and The Labor Market", Journal of Economic Literature, volume 40, pp. 7-72.

Bloom D., R. Freeman and S. Korenman (1987), "The labor market consequences of generational crowding", European Journal of Population, 3, pp. 131-76.

Boucekkine R., D. de la Croix and O. Licandro (2000), "Vintage Human Capital, Demographic Trends and Endogenous Growth", Institut de Recherches Economiques et Sociales (IRES) Discussion Paper 2000-007.

Charlot O. (2002), «Éducation et Chômage dans les modèles d'appariement ", thèse de doctorat, Univ. Paris I and Eurequa.

Charlot O. (2003), "Éducation, emploi et participation au marché du travail dans un modèle d'appariement ", forthcoming Recherches Économiques de Louvain.

Charlot O. and B. Decreuse (2004), "Self-selection in education and matching frictions", forthcoming in Labour Economics.

Coles M. and A. Masters (2000), 'Duration Dependent UI Payments in a Model of Equilibrium", ESSEX discussion paper.

de la Croix D. and F. Docquier (2003), "Diverging Patterns of Education Premium and School Attendance in France and the US: A Walrasian View", IZA Discussion Paper 846.

Davis S.J. (1992), "Cross-Country Patterns of Change in Relative Wage", NBER Macroannuals, pp. 239-292.

Gottschalk P. (1997), "Inequality, Income Growth, and Mobility: The Basic Facts", Journal of Economic Perpsectives, 11, pp. 21-40.

Juhn C., K. Murphy and B. Pierce (1993), "Wage Inequality and the Rise in Return to Skill", Journal of Political Economy, pp. 410-42.

Katz L. and K. Murphy (1992), "Changes in Relative Wages, 1963-1987 : Supply and Demand Factors", Quarterly Journal of Economics, February.

Mincer J. (1974), Schooling, Experience, and Earnings, National Bureau of Economic Research, New York.

Mincer J. (1997), "The Production of Human Capital and the Life Cycle of Earnings : Variations on a Theme", Journal of Labor Economics, 15(1), Part 2 January, pp. S26-47.

Murphy K.M, M. Plant and F.R. Welch (1988), "Cohort Size and Earnings in the USA", in Lee R.D., Arthur W.B. and Rodgers Gerry eds., Economics of changing age distributions in developed countries. International Studies in Demography series, Oxford University Press, Clarendon Press, pp. 39-58.

Ortega J. (2000), "Loss of Skill During Unemployment and Complementarities in the Production", the Economic Journal, vol. 110, n. 460, January, pp. 92112.

Pissarides C.A. (1990), Equilibrium Unemployment Theory, Oxford : Basil Blackwell, reedition MIT Press 2000.

Pissarides C.A. (1992), "Loss of Skill During Unemployment and the Persistence of Employment Shocks", Quarterly Journal of Economics, pp. 1371-1391, November.

Saint-Paul G. (1993), "On the Political Economy of Labor Market Flexibility", NBER Macroeconomics Annual. 
Saint-Paul G. (1995), "Labor Market Institutions and the Cohesion of the Middle class", discussion paper 1298, CEPR.

Shimer R. (1998), "Why is the U.S. unemployment rate so much lower?", NBER Macroannuals, pp. 11-72.

Wasmer E. (1997), "Changes in the Composition of the labor Force. Implications for Wages and Unemployment", PhD dissertation, Department of Economics, LSE.

Wasmer E. (1998), "Labor Supply Dynamics, Unemployment and Human Capital Investments", IIES Seminar Paper Series 98-651.

Wasmer E. (2001), "Measuring human capital in the labor market : the supply of experience in 8 OECD countries", European Economic Review Papers and Proceedings, Vol 45, $\mathrm{n}^{\circ} 4-6$, pp. 861-874.

Wasmer E. (2002), "Labor Supply Dynamics, Unemployment and Human capital Investments", $I Z A$, dp. 463.

Weiss Y. (1986), "The Determination of Life-Cycle Earnings : A survey", Ch. 11 in Handbook of Labor Economics, Vol. 1, O. Ashenfelter and R. Layard, eds.

Welch F. (1979), 'Effects of Cohort Size on Earnings: The Baby Boom Babies' Financial Bust", Journal of Political Economy, pp. S65-97. 